\title{
KAJIAN PERANCANGAN MOTIF "KOPI CENGKEH" PADA BATIK MALANGAN DENGAN TEKNIK SHAPE GRAMMAR
}

\author{
Titi Ayu Pawestri ${ }^{1^{*}}$, Debri Haryndia Putri ${ }^{2^{*}}$ \\ Program Studi D4 Desain Grafis Program Pendidikan Vokasi \\ Universitas Brawijaya \\ Jl. Veteran, Ketawanggede, Kec. Lowokwaru, Kota Malang, 65145. \\ Jawa Timur. Indonesia \\ Email: titipawestri@ub.ac.id
}

\begin{abstract}
Abstrak
Batik Malangan merupakan sebutan untuk karya seni batik dengan motif khas Malang dengan motifmotif alam yang terinspirasi dari lingkungan alam sekitar Malang Raya. Sebagai contoh beberapa komoditas hasil pertanian terbesar di Malang selatan seperti kopi dan cengkeh mampu memberikan inspirasi masyarakat dalam pembuatan motif batik. Batik Malangan memerlukan inovasi dalam pengembangan motifnya secara cepat dan tepat. Salah satu teknik yang dapat digunakan untuk memodifikasi motif dengan cepat adalah metode shape grammar dengan menggunakan software berbasis $C A D$ (computer aided design). Metode shape grammar adalah metode komposisi bentuk yang diformulasikan secara digital dengan bantuan software komputer agar motif yang dihasilkan dapat tampil lebih presisi dan berbeda. Metode penelitian yang dipakai pada penelitian ini adalah kualitatif deskriptif melalui pendekatan eksperimental. Metode kualitatif deskriptif digunakan untuk mengolah data awal hingga peneliti menemukan beberapa sample motif dominasi bentuk dasar Batik Malangan, kemudian setelah itu peneliti menggunakan metode shape grammar untuk uji coba hingga menemukan beberapa alternatif motif Batik Malangan. Hasil penelitian menunjukkan re-komposisi motif dengan menggunakan teknik shape grammar dan dapat menghasilkan berbagai alternatif desain motif Kopi Cengkeh dengan memberikan ciri khas dari kekayaan alam Malang.
\end{abstract}

Kata Kunci: batik, shape grammar,motif.

\begin{abstract}
Malangan Batik is a term for batik artwork with a typical Malang motif with natural motifs inspired by the natural environment around Malang. For example, some of the largest agricultural commodities in southern Malang, such as coffee and cloves, can inspire people to make batik motifs. Malangan Batik requires innovation in developing its motives quickly and precisely. One technique that can be used to modify motifs quickly is the shape grammar method using CAD (computer aided design) software. The shape grammar method is a form composition method that is formulated digitally with the help of computer software so that the resulting motif can appear more precise and different. The research method used in this study is descriptive qualitative through an experimental approach. Descriptive qualitative methods are used to process the initial data until researchers find several samples of predominant motifs of the basic form of Batik Malangan, then after that the researchers use the shape grammar method for testing to find several alternatives to the Malangan Batik motif. The results of the study showed the composition of motifs using the shape grammar technique and could produce various alternative designs of the Kopi Cengkeh motif by giving a characteristic of Malang's natural wealth.
\end{abstract}

Keywords: batik, shape grammar, motif.

\section{PENDAHULUAN}

Batik Indonesia secara resmi diakui UNESCO (United Nations Educational, Scientific, and Cultural Organization) pada tanggal 2 Oktober 2009 dengan dimasukkan ke dalam Daftar Representatif sebagai Budaya Tak-benda Warisan Manusia (Representative List of the Intangible Cultural Heritage of Humanity) dalam Sidang ke-4 Komite Antar-Pemerintah (Fourth Session of the Intergovernmental Committee) tentang
Warisan Budaya Tak-benda di Abu Dhabi (antaranews.com).

Keputusan ini berdasarkan dari kekayaan motif dalam ornamen batik yang tersebar di seluruh Indonesia, dimana di setiap daerah memiliki karakteristik motif yang berbeda-beda. Melalui motif, ide dasar sebuah ornamen dapat dikenali sebagai perwujudan motif yang merupakan gubahan dari bentukan di alam atau 
sebagai representasi alam yang kasat mata. Motifmotif batik ini umumnya terinspirasi dari alam sekitarnya yang menjadi karakteristik suatu daerah tertentu. Seperti daerah-daerah lain di Indonesia, Malang juga memiliki motif batik yang khas. Batik Malangan merupakan sebutan untuk karya seni batik dengan motif khas Malang yang terinspirasi dari kondisi fisik Malang. Malang selatan khususnya Sumbermanjingwetan dikenal dengan hasil buminya yang berupa kopi dan cengkeh (sumbermanjingwetan.malangkab.go.id).

Kopi AMSTIRDAM yang merupakan singkatan dari kecamatan di Malang yaitu Ampel gading, Sumbermanjing Wetan, Tirtoyudo, Dampit merupakan jenis kopi yang sudah populer di kalangan pecinta kopi nusantara yang tumbuh di daerah Malang selatan khususnya di empat kecamatan tersebut. Sedangkan komoditas cengkeh di daerah Sumbermaning Wetan selama ini dikenal sebagai salah satu wilayah penghasil cengkeh terbesar (malangtoday.net). Sehingga bentukan buah kopi yang masih utuh dan bunga cengkeh merupakan unsur keindahan potensi alam yang menjadi kebanggaan warga Malang selatan khususnya dan Malang raya pada umumnya. Seperti halnya daerah penghasil batik yang terinspirasi oleh alam, hal ini dapat memicu kreativitas para pengrajin batik Malangan agar selalu melakukan inovasi dan alternatif motif guna meningkatkan penjualan. Dengan adanya lebih banyak varian tentunya pelanggan akan mempunyai banyak pilihan motif yang jarang dijumpai atau bahkan belum pernah ada. Sehingga daya tarik inilah yang akan menjadi langkah awal dalam mendapatkan konsumen yang lebih banyak dan lebih luas dari sebelumnya. Dalam proses pembuatannya, sebenarnya batik identik dikaitkan dengan suatu proses dari mulai penggambaran motif, pencantingan dengan lilin (malam), pelorodan lilin

hingga pewarnaan. Salah satu yang menjadi ciri khas dari batik adalah proses pemalaman yaitu suatu teknik yang dilakukan dengan mengoreskan cairan lilin melalui alat yang bernama canting atau cap. Meskipun saat ini teknik printing yang lebih modern dan cepat sudah mulai dilakukan, teknik batik menggunakan malam/lilin ini masih terjaga keberlanjutannya. Untuk menjaga keberlanjutan eksistensi batik, perlu ada inovasi dalam teknik pembuatan motif, baik teknik pemalaman maupun teknik printing. Banyak cara pembuatan modifikasi motif tergantung kreativitas dari pengrajinnya. Salah satu teknik yang dapat digunakan untuk memodifikasi motif adalah metode shape grammar dengan menggunakan software berbasis CAD (Computer Aided Design). Metode
Gorga Jurnal Seni Rupa

Volume 08 Nomor 01 Januari-Juni 2019

p-ISSN: 2301-5942 | e-ISSN: 2580-2380

shape grammar adalah metode komposisi bentuk yang diformulasikan secara digital dengan bantuan software komputer agar motif yang dihasilkan dapat tampil berbeda dari sebelumnya dan hasilnya bisa lebih presisi. Metode ini akan diterapkan pada motif batik Malangan di Indonesia. Selanjutnya hasil dari teknik ini akan dianilisis dengan mengaitkan prinsip-prinsip desain, diantaranya adalah keseimbangan, irama, proporsi, pergerakan, emphasis, kesatuan dan dominasi. Di samping itu pemilihan komposisi warna juga akan dianalisis berdasarkan psikologi warna.

\section{KAJIAN TEORI}

\section{Teori Psikologi Warna}

Faktor eksternal merupakan persepsi warna secara umum dan dapat dijelaskan secara ilmiah. Masingmasing warna mempunyai karakteristik khusus yang menjelaskan sifat dan kegunaannya. Menurut Issac Newton warna merah mempunyai panjang gelombang terpanjang yakni $680 \mathrm{~nm}$, sehingga warna merah lebih cepat tertangkap oleh indera penglihatan dibandingkan warna lainnya. Warna-warna dengan nilai gelombang panjang lebih bersemangat begitu sebaliknya gelombang rendah mempunyai sifat yang menenangkan dan tidak terlalu mencolok. Berikut adalah penjelasan psikologi warna menurut Darmaprawira, 2002.

a. Merah: Keberanian, Kekuatan, Energi, Semangat, Adrenalin, vitalitas, bahaya, berani

b. Orange: Kehangatan, Kenyamanan, Keceriaan, ekstrim, menarik,

c. Kuning: Ceria, Bahagia, Energik, bijaksana dan Optimis

d. Hijau: Kesuburan, Kesegaran, Kedamaian, Keseimbangan, istirahat, tumbuh , kesegaran, tenang.

e. Biru: Stabil, Kecerdasan, Rasa Percaya Diri, tenang Relaksasi

f. Hitam: Hampa, Duka, keahlian , resmi dan Misterius

g. Putih:Bersih, Suci, Ringan dan Kebebasan

h. Cokelat: Hangat, tenang, alami, bersahabat dan rendah hati.

\section{Metode Shape Grammar}

Metode Shape grammar dihasilkan dari penerapan aturan algoritma. Algoritma adalah urutan atau langkah-langkah untuk penghitungan. Biasanya aturan ini berupa rumus-rumus numerik yang dapat dihitung secara matematis. Sehingga pengerjaannya lebih logis, presisi, konsisten dan saintifik. Contoh rumus-rumus yang sering digunakan dalam perhitungan metode shape grammar pada pembuatan konsep baru motif batik adalah rumus turunan kuadrat, kelipatan atau 


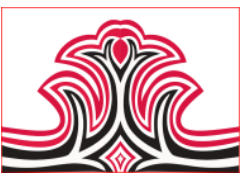

persamaan tertentu yang membentuk suatu pola. Di dalam metode mendesain atau menggambar sebuah konsep baru desain motif batik, penerapan algoritma akan tidak terlalu rumit. Metode yang dilakukan melalui penyatuan, substaksi (pengurangan), irisan, translasi (perpindahan), rotasi (perputaran), refleksi (pencerminan) dan skala. Beberapa metode tersebut dapat dicampurkan atau dikombinasikan dengan aturan tertentu sehingga menghasilkan bentukan yang lebih variatif. Dengan metode shape grammar akan terbentuk motif baru dalam suatu bidang media dengan cara penggandaan dan perulangan.

\section{1).Translasi}

Metode translasi merupakan suatu metode penemuan bentuk baru dengan cara memindahkan bentuk eksisting. Komponen akan dipindahkan ke kanan,ke kiri, ke atas, ke bawah ataupun serong dengan jarak tertentu. Jika menggunakan aturan algoritma, setiap perpindahan akan mempunyai pola atau rumus tertentu. Misal, menggunakan jarak yang sama, turunan kuadrat, rumus kelipatan atau rumus-rumus lainnya.

\section{2).Rotasi}

Bentuk baru yang dihasilkan melalui metode rotasi ini akan berbeda-beda tergantung dari besaran sudut putarnya. Sudut yang digunakan mempunyai titik putar yang sama dalam $360^{\circ}$. Pusat perputaran atau titik putarnya berada pada bidang komponen eksistingnya atau di luar.

\section{3).Refleksi}

Metode refleksi merupakan metode untuk menghasilkan bentukan baru dengan cara komponen eksisting dicerminkan dengan menggunakan garis pencerminan yang diletakkan di dalam bidang komponen ataupun di luarnya. Garis pencerminan dapat menggunakan garis vertikal, horisontal, ataupun sudut-sudut tertentu.

\section{4).Kombinasi}

Selain teknik-teknik di atas, masih banyak beberapa teknik yang bisa dilakukan dengan menggunakan metode shape grammar. Salah satu teknik yang lebih rumit dan kompleks adalah dengan mengkombinasikan 2 atau lebih beberapa teknik tersebut sehingga hasil bentukan baru lebih variatif. Misal setelah dipindahkan, komponen dicerminkan dengan garis tertentu begitu seterusnya.
Gorga Jurnal Seni Rupa

Volume 08 Nomor 01 Januari-Juni 2019

p-ISSN: 2301-5942 | e-ISSN: 2580-2380

\section{METODE PENELITIAN}

Metode penelitian yang dipakai pada penelitian ini adalah kualitatif deskriptif melalui pendekatan eksperimental. Metode kualitatif deskriptif digunakan untuk mengolah data awal dan menganalisis keadaan lingkungan sekitar Malang untuk menemukan beberapa sample motif bentuk dasar atau master Batik Malangan, kemudian setelah itu metode shape grammar diaplikasikan sebagai proses uji coba hingga menemukan beberapa alternatif motif Batik Malangan. Metode shape grammar adalah metode komposisi bentuk yang diformulasikan secara digital dengan bantuan software komputer agar motif yang dihasilkan dapat tampil lebih presisi dan berbeda (Ismail, Nor Fuzaina, Fuziyah Ishak, Jamaliahani Tumin, Nurzayani Yusup dan Eva Elvira Ruwipin, 2013). Metode shape grammar dapat digunakan untuk menghasilkan motif baru yang original didasarkan pada bentuk dan komposisi eksisting motif. Beberapa metode shape grammar yang dapat diterapkan dalam pengkomposisian motif seperti pengulangan, pencerminan baik secara horisontal dan vertikal maupun perputaran dengan berbagai sudut yang berbeda dapat menghasilkan alternatif motif yang beragam.

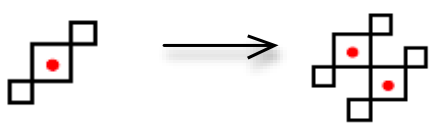

Gambar 1. Repetition Techniques (Sumber: Ismail, dkk, 2013)

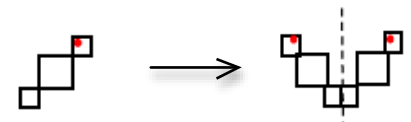

Gambar 2. Vertical Reflection Technique (Sumber: Ismail, dkk, 2013)

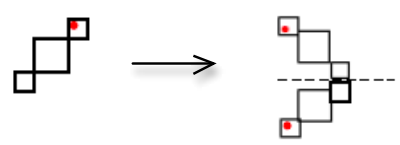

Gambar 3. Horizontal Reflection Technique (Sumber: Ismail, dkk, 2013)

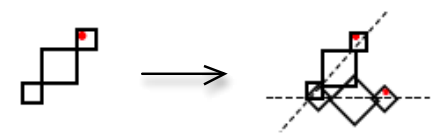

Gambar 4. Rotation Technique with Certain Angles (Sumber : Ismail, dkk, 2013) 


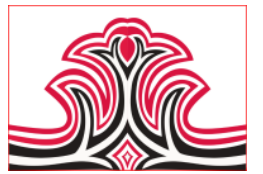

\section{HASIL DAN PEMBAHASAN}

\section{Hasil}

Dalam penciptaan motif batik, seorang perancang menggunakan unsur-unsur desain antara lain titik, garis, bidang dan pemilihan komposisi warna dengan berpedoman pada prinsip desain untuk mencapai sebuah estetika visual. Sehingga hasil karya desain dapat dinikmati dan diapresiasi oleh orang lain. Seorang perancang motif batik mengamati elemenelemen yang ada di sekitarnya untuk dijadikan inspirasi desain motif yang akan diciptakan. Metode shape grammar dapat juga memberikan beberapa alternatif motif baru pada batik Malangan. Motif master terinspirasi dari bentukan flora yang terdapat pada kabupaten Malang yaitu tanaman cengkeh yang juga komoditi terbesar di Sumbermanjing Wetan. Selain itu buah kopi khas dari Malang selatan akan memberikan bentukan baru dalam penciptaan sebuah motif batik Malangan. Dari perpaduan buah kopi dan bunga cengkeh akan menghasilkan satu desain motif baru yaitu motif kopi cengkeh.

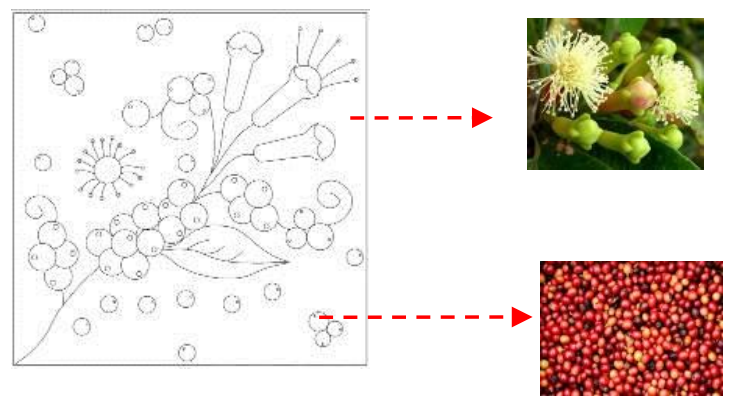

Gambar 5. Motif "Kopi Cengkeh"

(Sumber: Titi Ayu Pawesri, 2018)

Motif "kopi cengkeh" terdiri dari tiga bunga cengkeh. Salah satunya berupa bunga yang sedang mekar dan letaknya berada di antara dua bunga lainnya. Pada batangnya terdapat segerombol buah kopi beserta satu daun kopi. Di sisi lain bunga kopi yang mekar menjadi point of interest di antara sekumpulan buah kopi yang tersebar secara acak. Komposisi elemen-elemen ini merupakan pola asimetris yang dinamis, agar saat dilakukan uji coba shape grammar dapat membentuk komposisi motif yang berbeda-beda. Motif ini akan menjadi motif master yang selanjutnya akan diuji cobakan dalam metode shape grammar. Dalam metode shape grammar akan dilakukan uji coba berupa pencerminan vertikal, perputaran dengan sudut $90^{\circ}$, serta kombinasi dari berbagai teknik.

\section{1).Ujicoba Pencerminan Vertikal}

Pada uji coba refleksi vertikal, master motif dicerminkan oleh garis vertikal secara menyeluruh. Selanjutnya terjadi perulangan searah dan sejajar
Gorga Jurnal Seni Rupa

Volume 08 Nomor 01 Januari-Juni 2019

p-ISSN: 2301-5942 | e-ISSN: 2580-2380

dengan dicerminkan secara vertikal ke arah samping kanan dan kiri.

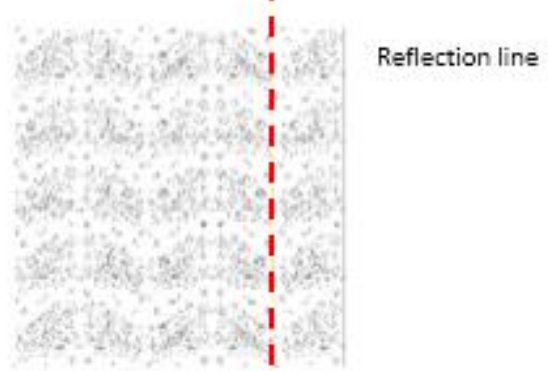

Gambar 6. vertical reflection (Sumber: Titi Ayu Pawesti, 2018)

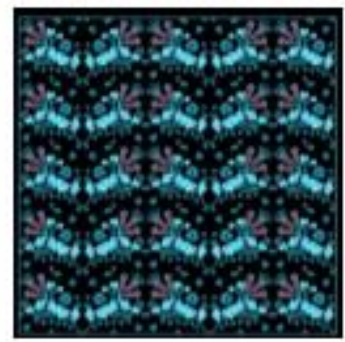

Gambar 7. Aplikasi Wama Refleksi Vertikal (Sumber: Titi Ayu Pawestri, 2018)

\section{2).Ujicoba Pencerminan Horizontal dan Vertikal}

Pada uji coba pencerminan vertikal dan horisontal, metode yang diterapkan adalah dengan mencerminkan pada garis vertikal dahulu kemudian hasil pencerminan itu dicerminkan lagi pada garis horisontal. Begitu seterusnya diulang ke bawah dengan pencerminan garis horizontal. 

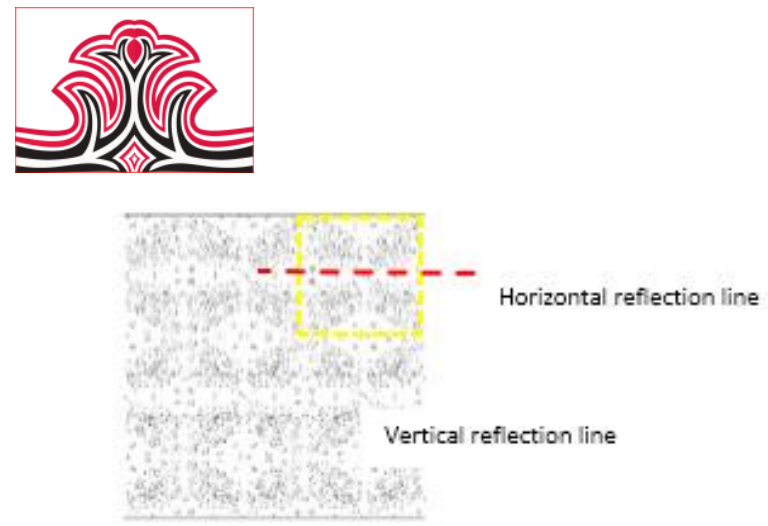

Gambar 8. Pencerminan Vertikal Horisontal Sumber: Titi Ayu Pawestri, 2018)

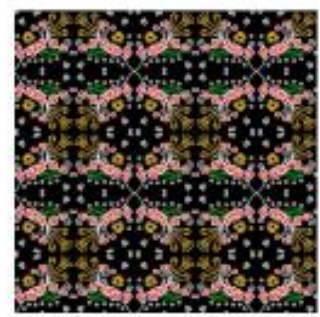

Gambar 9. Aplikasi Wama Pencerminan Vertikal Horisontal (Sumber: Titi Ayu Pawestri, 2018)

\section{3).Ujicoba Rotasi 90 Turun Satu Grid}

Pada uji coba refleksi putar sudut $90^{\circ}$ turun satu kotak, komposisi yang terjadi adalah menggunakan prinsip proporsi yang sifatnya lebih dinamis. Metode yang diterapkan adalah dengan cara hasil dari refleksi putar sudut $90^{\circ}$, direfleksikan ke samping turun satu grid atau kotak.

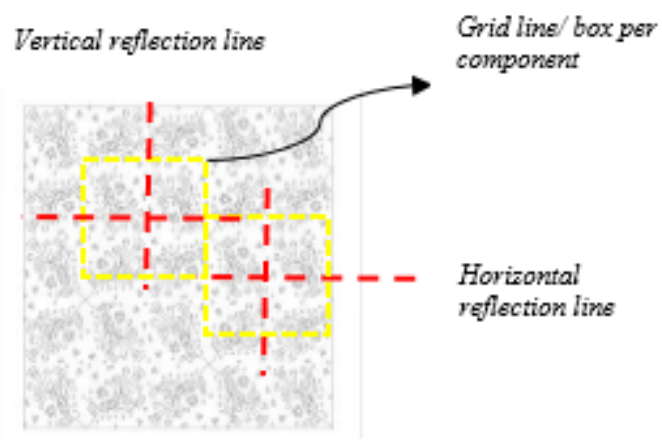

Gambar 10. Perputaran Sudut $90^{\circ}$ Turun Satu Grid (Sumber. Titi Ayu Pawestri, 2018)
Gorga Jurnal Seni Rupa

Volume 08 Nomor 01 Januari-Juni 2019 p-ISSN: 2301-5942 | e-ISSN: 2580-2380

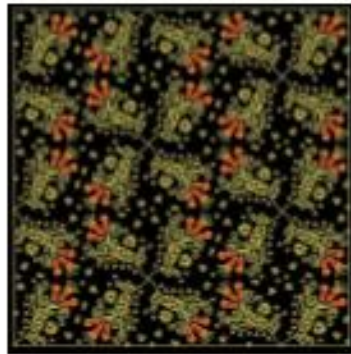

Gambar 11. Aplikasi Wama Perputaran Sudut $90^{\circ}$ Satu Grid Sumber: Titi Axu Rawestri, 2018)

\section{Pembahasan}

\section{1).Pencerminan Vertikal}

Dalam aplikasi warna, warna yang digunakan adalah warna hitam, putih, biru dan merah

- Biru sebagai representasi warna yang identik dengan klub sepakbola kebanggan masyarakat Malang yaitu AREMA FC. Warna biru merupakan warna ketenangan jiwa seseorang.

- Merah melambangkan semangat membara dari warga kota Malang

- Hitam merepresentasikan kepekatan dari sebuah biji kopi yang sudah diseduh dan memberikan kenikmatan yang mendalam

- Putih merepresentasikan warna pegunungan kapur yang tersebar pada kontur alam di Malang selatan.

Kombinasi warna tersebut merupakan kombinasi warna kontras antara biru dan merah. Kombinasi warna kontras merupakan kombinasi warna yang dinamis yang membuat mata yang memandang menjadi lebih semangat dan bergairah. Sedangkan warna hitam dan putih merupakan warna penyeimbang atau penetralisirnya.Secara keseluruhan motif ini melambangkan "kedewasaan merupakan simbol dari ketenangan pikiran akan tetapi jiwa harus tetap semangat membara".

\section{2).Pencerminan Vertikal dan Horizontal}

Dalam aplikasi warna, warna yang digunakan adalah warna hitam, putih, merah, hijau dan kuning.

- Kuning terdapat pada alam sekitar yaitu ada di warna-warna flora yang menarik dan ceria. Warna kuning ini merepresentasikan warna optimisme.

- Hitam merepresentasikan kepekatan dari sebuah biji kopi yang sudah diseduh dan memberikan kenikmatan yang mendalam

- Putih merepresentasikan warna pegunungan kapur yang tersebar pada kontur alam di Malang selatan. 


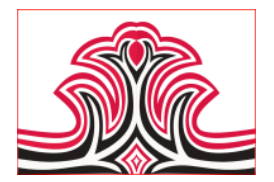

- Hijau representasi dari daun tanman kopi bermakna masyarakatnya menyatu dengan alam sekitar

- Merah representasi dari buah kopi yang sudah matang bermakna semangat yang membara.

Warna kuning sebagai warna yang kontras dari warna hitam dan putih latarnya, menjadikan warna kuning sebagai warna aksentuasi yang menampilkan keceriaan. Secara keseluruhan motif ini melambangkan "secercah asa dan optimisme di dalam keterpurukan yang menenggelamkan".

\section{3).Rotasi 90 ${ }^{\circ}$ Turun Satu Grid}

Dalam aplikasi warna, warna yang digunakan adalah warna hitam, putih, jingga dan kuning.

- Jingga dan kuning merupakan warna yang dihasilkan dari fenomena matahari terbit yang biasanya ditunggu-tunggu oleh wisatawan di gunung Bromo dan pantai-pantai selatan Malang. Warna-warna ini menunjukkan semangat dan optimisme.

- Hitam merepresentasikan kepekatan dari sebuah biji kopi yang sudah diseduh dan memberikan kenikmatan yang mendalam

- Putih merepresentasikan warna pegunungan kapur yang tersebar pada kontur alam di Malang selatan.

Kombinasi warna analog jingga dan kuning merupakan kombinasi warna yang selaras. Sangat sesuai untuk diaplikasikan ke dalam komposisi motif batik yang ingin menampilkan kehangatan. Latar belakang warna hitam akan menampilkan kekontrasan dari motifnya sehingga motif batik akan semakin menonjol dan "bersuara". Secara keseluruhan motif ini melambangkan "menjadi seseorang yang berpengaruh serta bersinar haruslah membawa pelita dalam kegelapan".

Tabel 1. Kesimpulan Hasil Uji Coba Motif Kopi Cengkeh

\begin{tabular}{|c|c|}
\hline Hasil Motif Uji Coba & Analisis \\
\hline 1. Refleksi Verti & \\
\hline 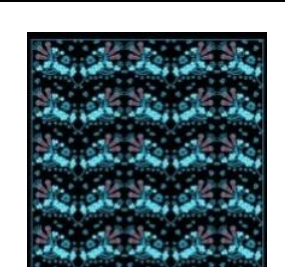 & $\begin{array}{l}\text { prinsip berirama } \\
\text { menyerupai bentukan } \\
\text { ombak } \\
\text { - warna biru, hitam dominan } \\
\text { dan merah sebagai } \\
\text { aksentuasi }\end{array}$ \\
\hline \multicolumn{2}{|c|}{ Refleksi vertikal horisontal } \\
\hline
\end{tabular}

Gorga Jurnal Seni Rupa

Volume 08 Nomor 01 Januari-Juni 2019

p-ISSN: 2301-5942 | e-ISSN: 2580-2380

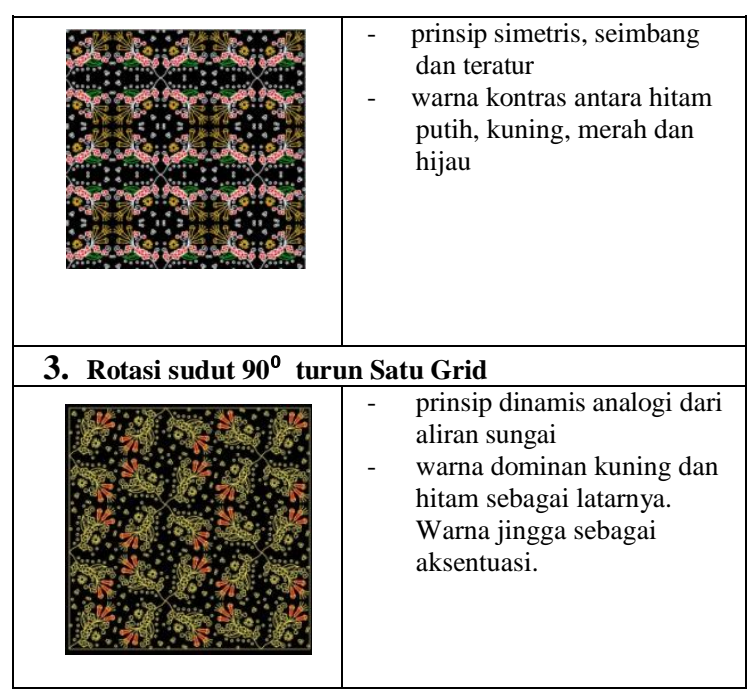

\section{KESIMPULA DAN SARAN}

\section{Kesimpulan}

Pengembangan desain motif kopi dengan menambahkan cengkeh pada desain masternya dapat dijadikan alternatif motif yang dapat mempromosikan komoditas pertanian Malang Selatan ke dalam desain motif batik. Pemilihan warna yang disesuaikan dengan lingkungan, sosial dan budaya masyarakat Malang semakin memperkuat identitas dari batik Malangan. Penelitian ini menawarkan metode yang lebih efisien dalam menciptakan pola motif batik baru sebagai alternatif desain motif batik Malangan. Teknik digitalisasi pada metode shape grammar akan lebih memudahkan produsen batik dalam proses produksi batik skala besar dengan menggunakan peralatan cap dan printing. Karena software Autocad mampu memberikan output plotting yang bisa dicetak dengan terskala di ukuran apapun dengan cepat dan mudah.

\section{Saran}

Dalam upaya pengembangan potensi komoditas batik Malangan, perlu adanya kajian yang membahas tentang kekayaan alam, sosial dan budaya Malang raya, agar dalam menciptakan sebuah motif batik sudah melalui analisis yang tepat dan sesuai dengan identitas Malang. Program yang dapat dilakukan oleh pemerintah yang sejalan dengan penelitian ini adalah dengan mengadakan workshop penciptaan motif batik secara digital dan diikuti oleh masyarakat umum, baik pengrajin batik maupun masyarakat awam. Selanjutnya mengadakan sayembara penciptaan batik atau memberikan hibah penelitian khusus batik Malangan, sehingga dengan langkah ini batik Malangan dapat terus lestari. 


\section{DAFTAR RUJUKAN}

Darmaprawira, Sulasmi. (2002). Warna Teori Kreativitas dan Penggunaannya. Bandung: ITB.

Fikri,Dimas. (2018). Mengintip Proses Produksi Minyak Cengkeh yang Berkualitas di Sumawe. Diunduh 17 April 2019 (Online). Di www.malangtoday.net

Ismail, Nor Fuzaina, Fuziyah Ishak, Jamaliahani Tumin, Nurzayani Yusup dan Eva Elvira Ruwipin. (2013). Geometric Shapes Generation in Songket Designs Using Shape grammar, Kuala Lumpur: Proceedings of the 12th International Conference on Applied Computer and Applied Computational Science (ACACOS'13), , pp.153-157.

Stiny, G, and J. Gips. 1972. Shape grammars and the Generative Specification of Painting and Sculpture.In: Information Processing 71, ed. C. V. Freiman, , pp.1460-1465.

sumbermanjingwetan.malangkab.go.id, diakses 15 Agustus 2018

Surya. (2009). Batik Indonesia Resmi Diakui UNESCO. Diunduh 30 Agustus 2018 (Online). Di www.antaranews.com. 